\title{
Article \\ Factors Affecting the Intention to Modify Lifestyle in the
Cardiovascular Disease Risk Group in Korea
}

JaeLan Shim ${ }^{1}$ a and KyungAe Kim ${ }^{2, *(\mathbb{D})}$

1 Department of Nursing, Dongguk University, Seoul 38066, Korea; jrshim@dongguk.ac.kr

2 College of Nursing, Kyungdong University, Wonju 26495, Korea

* Correspondence: kimkyungae9806@gmail.com; Tel.: +82-33-738-1440

Citation: Shim, J.; Kim, K. Factors Affecting the Intention to Modify Lifestyle in the Cardiovascular Disease Risk Group in Korea. Healthcare 2021, 9, 496. https:/ / doi.org/10.3390/healthcare9050496

Academic Editor: Pedram Sendi

Received: 13 March 2021

Accepted: 20 April 2021

Published: 22 April 2021

Publisher's Note: MDPI stays neutral with regard to jurisdictional claims in published maps and institutional affiliations.

Copyright: (c) 2021 by the authors. Licensee MDPI, Basel, Switzerland. This article is an open access article distributed under the terms and conditions of the Creative Commons Attribution (CC BY) license (https:// creativecommons.org/licenses/by/ $4.0 /)$.

\begin{abstract}
This study aimed to identify people at risk of cardiovascular diseases (CVD) using the Framingham risk score (FRS) and to examine their willingness to modify their lifestyle. A descriptive correlational study with 1229 participants, aged 30-74 years, without cardiovascular or cerebrovascular diseases who visited a health examination center in South Korea was conducted. Of 1229 participants, 455 were identified as high risk for CVD with an FRS of 10 or higher. A logistic regression analysis confirmed age, sex, muscle training, and weekly drinking frequency as predictors of intention to quit smoking; age, smoking, and waist to height ratio (WHtR) as predictors of intention to quit drinking; sex and WHtR as predictors of intention to engage in physical exercise; and hypertension and body mass index as predictors of intention of muscle training. People at high risk for CVD lack willingness to modify their lifestyle, and aggressive, customized intervention is needed to promote lifestyle modification.
\end{abstract}

Keywords: cardiovascular disease; FRS; lifestyle modification; risk; intention

\section{Introduction}

Cardiovascular disease (CVD) is the leading cause of death worldwide. According to the 2019 Statistics Korea report, it is the second leading cause of death following malignant neoplasm, with 117.4 deaths per 100,000 people [1]. Chronic diseases such as CVD are multifactorial and have multiple etiologies, rendering early diagnosis difficult. Furthermore, the time of disease onset is unclear and there is a long latent period. Thus, prevention, as opposed to treatment, is the focus for chronic diseases, which calls for screening of people at a high risk for CVD [2].

In 2014, Korea designated the first week of every September as the cardiovascular and cerebrovascular diseases prevention week, during which the government strives to reduce CVD mortality by launching the Red Circle Campaign. It increases awareness of and promotes compliance with the prevention and management of severe cardiovascular diseases such as myocardial infarction and stroke [3].

Considering that heart disease remains one of the leading causes of death despite advances in medical technology and development of novel drugs, it is important to note that other factors contribute to the incidence of heart disease. [4]

While many countries have strived to regulate these CVD risk factors and have announced their success in reducing CVD mortality [4], the Korean National Health and Nutrition Examination Survey (KNHANES) reports that health management pertaining to diseases that contribute to CVD morbidity, such as diabetes mellitus (DM), hypertension, and hyperlipidemia, is inadequate in Korea [5]. This highlights the need for more aggressive and preventive efforts in the country.

Cardiovascular disease risk factors can be categorized into two groups: modifiable and non-modifiable risk factors. Non-modifiable cardiovascular disease risk factors are those that cannot be changed. These include a person's age, ethnicity, and family history 
(genetics cannot be changed), among other factors. Modifiable cardiovascular disease risk factors are those that can be reduced or controlled with behavioral changes [6].

Some of the preventable risk factors of CVD include smoking, hypertension, DM, hyperlipidemia, obesity, and lack of exercise [7-9]. Furthermore, people who abuse alcohol are at 1.5-2.0-times greater risk of developing an ischemic heart disease compared to their non-drinking counterparts $[7,10]$. Therefore, the importance of CVD-related lifestyle modification has been emphasized.

The Framingham risk score (FRS) is a simple tool widely used to predict the level of CVD risk in the next 10 years, and it provides guidelines for managing risk factors [11,12]. In particular, the FRS for Coronary Heart Disease (FRS-CHD) predicts the incidence of coronary heart disease, including death from angina pectoris, myocardial infarction, and coronary artery disease, in the next 10 years, by sex in adults aged 30-74 years [13]. This tool accurately and efficiently predicts CVD and the risk of death because it assesses multiple factors, such as age, smoking, DM, systolic (SBP) and diastolic blood pressure (DBP), total cholesterol, and high-density lipoprotein cholesterol (HDL-C) [12,13].

A Korean study using FRS confirmed the factors affecting FRS by sex [14], and another study identified the factors influencing middle-aged women's lifestyle habits according to their FRS level that affect their 10-year cardiovascular disease risk [15]. Other studies have explored the relationship between FRS and carotid intima media thickness [16] and the relationship between the Fracture Risk Assessment Tool and FRS [17]. The findings of these studies suggest the need for a large-scale prospective study.

The purpose of the present study was to classify risk groups using FRS and to identify the factors that influence the willingness to improve lifestyle, which is a modifiable risk factor. We hypothesized the following:

- Among participants with moderate or high cardiovascular risk, the better the lifestyle habits, the higher their intention to quit smoking.

- Among participants with moderate or high cardiovascular risk, the better the lifestyle habits, the higher their intention to stop drinking.

- Among participants with moderate or high cardiovascular risk, the better the lifestyle habits, the higher their intention to engage in physical activity.

- Among participants with moderate or high cardiovascular risk, the better the lifestyle habits, the higher their intention to engage in strength exercises.

\section{Materials and Methods}

\subsection{Research Design}

This study employed a cross-sectional study design to identify, through influencing with CVD risk, participants' intentions to modify their lifestyle habits.

\subsection{Setting and Sample}

A total of 1282 people aged 30-74 years [13] who underwent a health examination at a health examination center in Korea from June 1 to July 31, 2020 were enrolled in this study. Data were collected via physical examination, blood tests, and a self-report questionnaire. A total of 34 individuals diagnosed with a heart disease (e.g., angina, myocardial infarction) or currently taking medications and 19 people diagnosed with and currently taking medications for cerebrovascular disease (stroke, cerebral hemorrhage) were excluded from the study [13]. As a result, a total of 1229 participants were included in the analysis (Figure 1). 


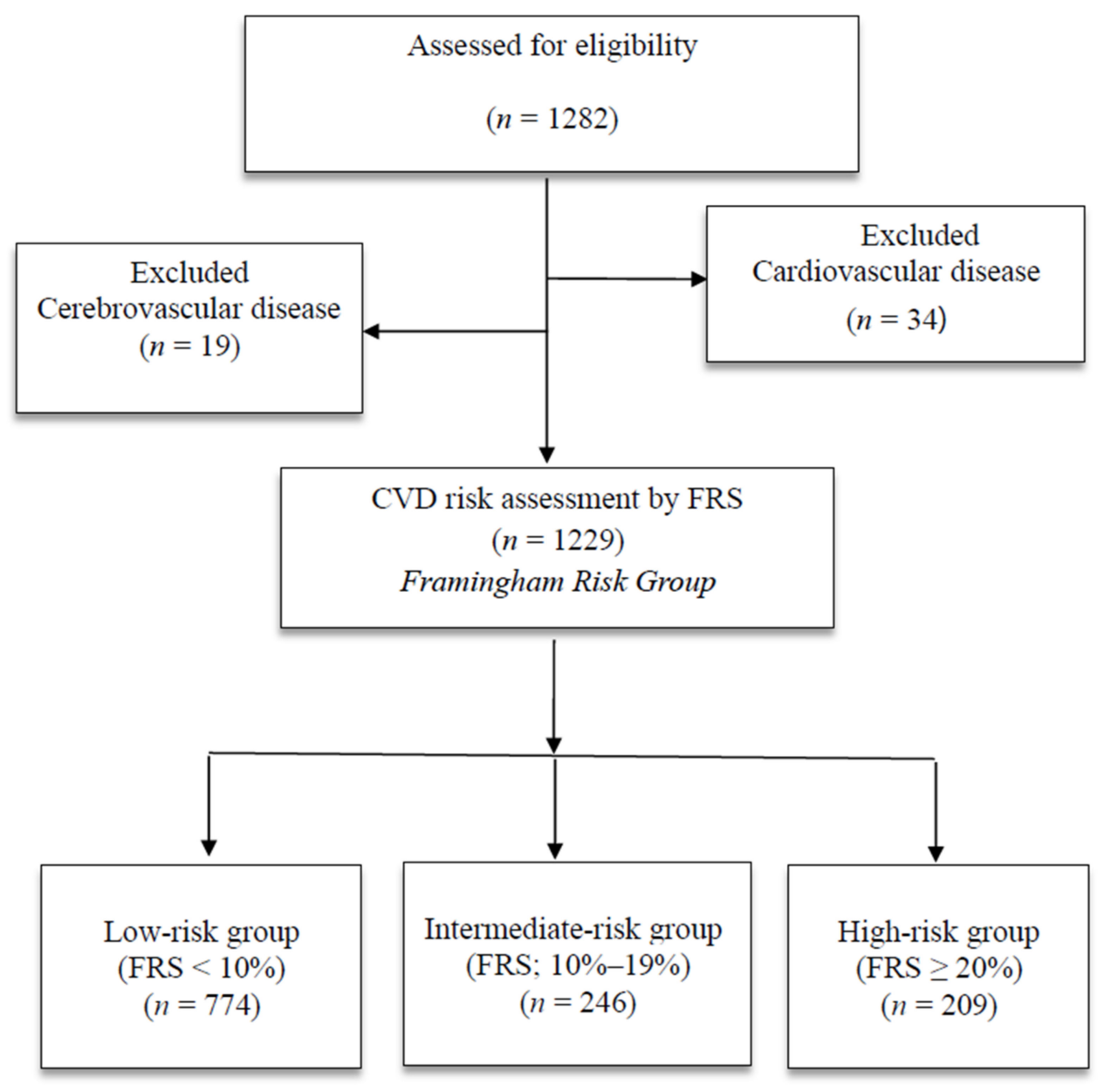

Figure 1. Flow chart of the study population; HDL = high-density lipoprotein.

\subsection{Measurements}

\subsubsection{General and Lifestyle-Related Characteristics}

Participants' demographic and lifestyle-related information, namely, age, sex, drinking, and smoking, was surveyed using the pre-exam health questionnaire. Information about physical activity was collected using the International Physical Activity Questionnaire (IPAQ) [18], specifically the number of times and duration of high-intensity physical activity that caused shortness of breath in the past week (e.g., running, aerobics, cycling, carrying things using the stairs) and moderate-intensity physical activity that caused mild shortness of breath (e.g., fast walking, tennis doubles, carrying light objects, cleaning). In accordance with the American Heart Association (AHA) Guidelines [19], people who engage in at least 150 min of moderate-intensity physical activity per week, 75 min of high-intensity physical activity per week, or at least two sessions of muscle training per week are considered to be engaging in sufficient physical activity.

\subsubsection{Hematologic Test}

For the blood test, the participants were informed in advance to refrain from overeating, drinking, and smoking, and to skip their medications as they may affect the test results. All participants fasted for at least eight hours prior to the blood test. Fasting glucose, HDL-C, total cholesterol, aspartate aminotransferase (AST), gamma glutamyl transpeptidase (GGT), and creatinine (Cr) levels were analyzed. Blood tests were performed by three clinical pathologists with more than 10 years of experience working at the institution where this study was conducted. The pathologists receive a training session once a year on drawing blood accurately. 


\subsubsection{Intention to Improve Lifestyle}

Participants' intentions to improve their lifestyle pertaining to smoking, drinking, physical exercise, and muscle training were examined using a self-report questionnaire, with "yes" or "no" responses.

\subsubsection{Framingham Risk Score-Coronary Heart Disease (FRS-CHD)}

The FRS was calculated by scoring participants' age, HDL-C, total cholesterol, SBP, $\mathrm{DM}$, and smoking status according to their sex, as per the calculation method presented in the Framingham heart study [13]. This calculation method classifies people into 10 age groups in 4-year units from the age of 30 . In step 2, people are classified into five groups according to total cholesterol and HDL-C by sex. In step 3, people are divided into six groups according to SBP by sex. In step 4, people are scored according to DM and smoking status (non-smoker, current smoker). In step 5, the scores are summed to calculate the total score, based on which an individual's 10-year risk for cardiovascular and cerebrovascular disease is estimated. The risk estimate is then used to classify the participants into low-risk $(<$ FRS $10 \%)$, intermediate-risk (10-19\%), and high-risk groups $(\geq 20 \%)[12]$.

\subsection{Ethical Considerations}

This study was approved by the Institutional Review Board of the research facility (IRB No. 130750-202002-HR-001) prior to data collection. After explaining the purpose of this study to the research participants, written informed consent was obtained from the participants prior to the health examination.

\subsection{Statistical Analysis}

The data were analyzed using SPSS/WIN 23.0 software (IBM SPSS Statistics, Chicago, IL, USA). The general characteristics were analyzed using descriptive statistics, namely, frequency and percentage. Differences in demographics and willingness to modify lifestyle according to the CVD risk category were analyzed with a one-way analysis of variance (ANOVA). The predictors of willingness to modify lifestyle in 455 participants in the intermediate-risk and high-risk groups (FRS $\geq 10 \%$ ) were analyzed using binary logistic analysis.

\section{Results}

\subsection{Differences in General Characteristics and Intention to Modify Lifestyle According to CVD Risk Category}

The mean age significantly differed among the low-risk group (54.6 \pm 10.7 years), intermediate-risk group ( $62.0 \pm 7.7$ years), and high-risk group ( $65.4 \pm 5.7$ years) $(F=135.1$, $p<0.001)$. In terms of sex, $667(87.5 \%)$ in the low-risk group and $149(60.6 \%)$ in the intermediate-risk group were women, while $184(88.0 \%)$ in the high-risk group were men.

The prevalence of DM significantly differed among the low-risk group $(n=34,4.4 \%)$, intermediate-risk group $(n=42,20.6 \%)$, and high-risk group $(n=47,22.5 \%)(F=76.87$, $p<0.001)$. The percentage of current smokers also significantly differed in the high-risk group $(n=158,75.6 \%$ ) compared to the low-risk and intermediate-risk groups ( $F=380.34$, $p<0.001)$. The percentage of people who drank alcohol at least once a week was significantly higher in the high-risk group $(n=87,41.6 \%)(F=43.88, p<0.001)$. In terms of intention to quit smoking, the majority in all three groups had no intention to quit smoking, with a significant difference among the groups $(F=56.55, p<0.001)$. In terms of intention to quit drinking, only $28.2 \%$ of the high-risk group were willing to quit drinking, with a significant difference among the three groups $(F=8.78, p=0.012)($ Table 1$)$. 
Table 1. Differences in general characteristics and intention to modify lifestyle according to FRS $(N=1229)$.

\begin{tabular}{|c|c|c|c|c|c|c|}
\hline \multirow[t]{2}{*}{ Variable } & \multirow[t]{2}{*}{ Category } & $\begin{array}{c}\text { Low-Risk } \\
\text { Group } \\
(n=774)\end{array}$ & $\begin{array}{c}\text { Intermediate-Risk } \\
\text { Group } \\
(n=246)\end{array}$ & $\begin{array}{l}\text { High-Risk } \\
\text { Group } \\
(n=209)\end{array}$ & \multirow[t]{2}{*}{$x^{2}$} & \multirow[t]{2}{*}{$p$} \\
\hline & & \multicolumn{3}{|c|}{$n(\%)$ or $\mathrm{M} \pm \mathrm{SD}$} & & \\
\hline \multicolumn{2}{|l|}{ Age (years) * } & $54.6 \pm 10.7$ & $62.0 \pm 7.7$ & $65.4 \pm 5.7$ & 135.19 & $<0.001$ \\
\hline \multirow{2}{*}{ Sex } & Male & 97 (12.5) & 97 (39.4) & 184(88.0) & 451.40 & $<0.001$ \\
\hline & Female & $677(87.5)$ & $149(60.6)$ & $25(12.0)$ & & \\
\hline \multirow{2}{*}{$\mathrm{DM}$} & Yes & $34(4.4)$ & $42(20.6)$ & $47(22.5)$ & 76.87 & $<0.001$ \\
\hline & No & 740 (95.6) & $204(79.4)$ & $162(77.5)$ & & \\
\hline \multirow{2}{*}{ Hypertension } & Yes & $97(12.5)$ & 77 (31.3) & $96(45.9)$ & 12272 & $<00001$ \\
\hline & No & 677 (87.5) & 169 (68.7) & $113(54.1)$ & 122.72 & $<0.001$ \\
\hline \multirow{2}{*}{ Dyslipidemia } & Yes & $68(8.8)$ & $34(13.8)$ & $14(6.7)$ & & \\
\hline & No & $706(91.2)$ & $212(86.2)$ & $195(93.3)$ & 7.75 & 0.21 \\
\hline \multirow{2}{*}{ Current smoking } & Yes & 77 (10.0) & $74(30.1)$ & $158(75.6)$ & \multirow[b]{2}{*}{380.34} & \multirow{2}{*}{$<0.001$} \\
\hline & No & $696(90.0)$ & $172(69.9)$ & $51(24.4)$ & & \\
\hline \multirow{2}{*}{$\begin{array}{l}\text { Alcohol consumption } \\
\text { (more than once/week) }\end{array}$} & Yes & 152 (19.6) & $56(22.8)$ & 87 (41.6) & \multirow[b]{2}{*}{43.88} & \multirow{2}{*}{$<0.001$} \\
\hline & No & $622(80.4)$ & $190(77.2)$ & $122(58.4)$ & & \\
\hline \multirow{2}{*}{$\begin{array}{l}\text { Vigorous physical activity } \\
\text { (over } 150 \mathrm{~min} / \text { week) }\end{array}$} & Yes & $116(15.0)$ & $32(13.0)$ & $26(12.4)$ & \multirow[t]{2}{*}{1.21} & \multirow[t]{2}{*}{0.543} \\
\hline & No & $658(85.0)$ & $214(87.0)$ & $183(87.6)$ & & \\
\hline \multirow{2}{*}{$\begin{array}{l}\text { Moderate physical activity } \\
\text { (over } 300 \mathrm{~min} / \text { week) }\end{array}$} & Yes & 143 (18.5) & $55(22.4)$ & $50(23.9)$ & \multirow[t]{2}{*}{3.94} & \multirow[t]{2}{*}{0.140} \\
\hline & No & $631(81.5)$ & $191(77.6)$ & $159(76.1)$ & & \\
\hline \multirow{2}{*}{$\begin{array}{l}\text { Muscle strengthening exercise } \\
\text { (more than twice/week) }\end{array}$} & Yes & 146 (18.9) & $50(20.3)$ & $52(24.9)$ & \multirow[t]{2}{*}{3.70} & \multirow[t]{2}{*}{0.157} \\
\hline & No & $628(81.1)$ & $196(79.7)$ & $157(75.1)$ & & \\
\hline \multirow{2}{*}{ Intention to quit smoking } & Yes & $46(5.9)$ & $30(12.2)$ & $49(23.4)$ & \multirow[t]{2}{*}{56.55} & \multirow[t]{2}{*}{$<0.001$} \\
\hline & No & $728(94.1)$ & $216(87.8)$ & $160(76.6)$ & & \\
\hline \multirow{2}{*}{ Intention to stop drinking } & Yes & 148 (19.1) & $47(19.1)$ & $59(28.2)$ & \multirow[t]{2}{*}{8.78} & \multirow[t]{2}{*}{0.012} \\
\hline & No & $626(80.9)$ & $199(80.9)$ & $150(71.8)$ & & \\
\hline Intention to donhvsical activity & Yes & $293(37.9)$ & $89(36.2)$ & $85(40.7)$ & 0.98 & 0.611 \\
\hline Intention to dophysical activity & No & $481(62.1)$ & $157(63.8)$ & $124(59.3)$ & & \\
\hline & Yes & $604(78.0)$ & $192(78.0)$ & $151(72.2)$ & 3.29 & 0.193 \\
\hline Intention to do strength exercise & No & $170(22.0)$ & $54(22.0)$ & $58(27.8)$ & & \\
\hline
\end{tabular}

Abbreviations: SD: standard deviation; DM: diabetes mellitus; FRS: Framingham risk score; Framingham risk score classification: high-risk group (FRS $\geq 20 \%$ ), intermediate-risk group (FRS: 10-19\%), Low-risk group (FRS < 10\%). * analyzed by ANOVA.

\subsection{Differences in Blood Test Results According to FRS Category}

Table 2 shows the differences in the blood test results according to the FRS category. Body mass index (BMI) was highest in the high-risk group $\left(24.9 \pm 2.9 \mathrm{~kg} / \mathrm{m}^{2}\right)$, with a significant difference among the three groups $(\mathrm{F}=16.61, p<0.001)$. Waist to height ratio (WHtR) was high in the intermediate- and high-risk groups $(0.53 \pm 0.1)$, with a significant difference among the three groups $(\mathrm{F}=15.94, p<0.001)$.

Table 2. Differences in hematologic tests according to FRS $(N=1229)$.

\begin{tabular}{|c|c|c|c|c|c|}
\hline \multirow[t]{2}{*}{ Variable } & $\begin{array}{c}\text { Low Risk } \\
\text { Group } \\
(n=774)\end{array}$ & $\begin{array}{c}\text { Intermediate Risk } \\
\text { Group } \\
(n=246)\end{array}$ & $\begin{array}{c}\text { High Risk } \\
\text { Group } \\
(n=209)\end{array}$ & \multirow[t]{2}{*}{ F or $\chi^{2}$} & \multirow[t]{2}{*}{$p$} \\
\hline & \multicolumn{3}{|c|}{ n $(\%)$ or $M \pm S D$} & & \\
\hline Systolic & $117.2 \pm 10.1$ & $126.9 \pm 12.2$ & $127.4 \pm 14.1$ & 110.84 & $<0.001$ \\
\hline BP (mmHg) Diastolic & $72.7 \pm 7.9$ & $76.7 \pm 8.9$ & $76.6 \pm 9.3$ & 31.88 & $<0.001$ \\
\hline $\operatorname{BMI}\left(\mathrm{kg} / \mathrm{m}^{2}\right)$ & $23.8 \pm 3.1$ & $24.9 \pm 3.1$ & $24.9 \pm 2.9$ & 16.61 & $<0.001$ \\
\hline WHtR & $0.51 \pm 0.1$ & $0.53 \pm 0.1$ & $0.53 \pm 0.1$ & 15.94 & $<0.001$ \\
\hline Fasting glucose (mg/dL) & $95.0 \pm 15.9$ & $204 \pm 82.9$ & $110.1 \pm 31.7$ & 47.19 & $<0.001$ \\
\hline HDL cholesterol(mg/dL) & $57.5 \pm 11.4$ & $51.0 \pm 10.4$ & $47.5 \pm 9.8$ & 84.96 & $<0.001$ \\
\hline Total cholesterol (mg/dL) & $202.1 \pm 37.9$ & $201.9 \pm 44.0$ & $191.5 \pm 45.2$ & 5.90 & 0.003 \\
\hline $\operatorname{AST}(\mathrm{mg} / \mathrm{dL})$ & $25.8 \pm 10.3$ & $27.0 \pm 9.0$ & $30.4 \pm 23.4$ & 10.19 & $<0.001$ \\
\hline GGT (IU/L) & $26.0 \pm 43.2$ & $32.2 \pm 30.6$ & $52.6 \pm 112.8$ & 16.53 & $<0.001$ \\
\hline $\mathrm{Cr}(\mathrm{mg} / \mathrm{dL})$ & $0.8 \pm 0.1$ & $0.9 \pm 0.15$ & $1.0 \pm 0.1$ & 149.88 & $<0.001$ \\
\hline
\end{tabular}

Abbreviations: SD: standard deviation; BP: blood pressure; BMI: body mass index; WHtR: waist to height ratio; HDL: high-density lipoprotein; AST: aspartate aminotransferase; GGT: gamma glutamyl transpeptidase; Cr: Creatinine. 


\subsection{Predictors of Intention to Modify Lifestyle in At-Risk CVD Groups}

The predictors of intention to modify lifestyle in at-risk CVD groups were analyzed for 455 participants in the intermediate-risk (FRS $\geq 10 \%$ ) and high-risk groups (FRS $\geq 19 \%$ ) (Table 3).

Table 3. Predictors of intention to modify lifestyle in at-risk CVD groups $(\mathrm{N}=455)$.

\begin{tabular}{|c|c|c|c|c|c|}
\hline Outcome Variable & B & $p$ & OR & \multicolumn{2}{|c|}{$95 \% \mathrm{CI}$} \\
\hline Factor & & & & Lower & Upper \\
\hline \multicolumn{6}{|c|}{ Intention to quit smoking } \\
\hline Age & 0.14 & $<0.001$ & 1.15 & 1.11 & 1.20 \\
\hline $\operatorname{Sex}^{\dagger}$ & 1.78 & $<0.001$ & 5.95 & 3.18 & 11.13 \\
\hline Frequency of strength exercise (per week) & 0.16 & 0.015 & 1.17 & 1.03 & 1.33 \\
\hline Frequency of drinking (per week) & 0.24 & 0.009 & 1.27 & 1.06 & 1.51 \\
\hline $\mathrm{WHtR}^{+}$ & 0.37 & 0.129 & 1.45 & 0.90 & 2.33 \\
\hline \multicolumn{6}{|c|}{ Model test: Chi-square $=294.09, p<0.001$, Nagelkerke $R^{2}=0.418$} \\
\hline \multicolumn{6}{|c|}{ Intention to stop drinking } \\
\hline Age & 0.73 & $<0.001$ & 1.08 & 1.05 & 1.10 \\
\hline $\operatorname{Sex}^{+}$ & 0.36 & 0.117 & 1.44 & 0.91 & 2.27 \\
\hline $\begin{array}{c}\text { Frequency of strength exercise } \\
\text { per week) }\end{array}$ & -0.02 & 0.650 & 0.10 & 0.90 & 1.07 \\
\hline Smoking ${ }^{+}$ & 1.33 & $<0.001$ & 3.78 & 2.39 & 6.00 \\
\hline $\mathrm{WHtR}^{+}$ & -0.39 & 0.028 & 0.68 & 0.48 & 0.96 \\
\hline \multicolumn{6}{|c|}{ Model test: Chi-square $=15.84, p<0.001$, Nagelkerke $R^{2}=0.243$} \\
\hline \multicolumn{6}{|c|}{ Intention to do physical exercise } \\
\hline Age & -0.02 & 0.201 & 0.99 & 0.97 & 1.00 \\
\hline Sex $^{\dagger}$ & -0.91 & $<0.001$ & 0.40 & 0.27 & 0.61 \\
\hline Smoking ${ }^{+}$ & 0.03 & 0.909 & 1.03 & 0.67 & 1.59 \\
\hline Frequency of drinking (per week) & 0.03 & 0.990 & 1.00 & 0.65 & 1.54 \\
\hline $\mathrm{WHtR}^{+}$ & -0.31 & 0.041 & 0.73 & 0.54 & 0.99 \\
\hline \multicolumn{6}{|c|}{ Model test: Chi-square $=60.36, p<0.001$, Nagelkerke $R^{2}=0.070$} \\
\hline \multicolumn{6}{|l|}{ Intention to do strength exercise } \\
\hline Age & 0.01 & 0.160 & 1.01 & 1.00 & 1.03 \\
\hline $\operatorname{Sex}^{+}$ & 0.40 & 0.161 & 1.50 & 0.85 & 2.64 \\
\hline Smoking ${ }^{+}$ & 0.05 & 0.881 & 1.05 & 0.58 & 1.88 \\
\hline Frequency of drinking (per week) & -0.32 & 0.115 & 0.73 & 0.49 & 1.08 \\
\hline Diabetes mellitus & 0.33 & 0.359 & 1.40 & 0.68 & 2.89 \\
\hline Hypertension $^{\dagger}$ & 0.62 & 0.007 & 1.85 & 1.18 & 2.90 \\
\hline Body mass index ${ }^{\dagger}$ & 0.52 & 0.001 & 1.69 & 1.23 & 2.32 \\
\hline
\end{tabular}

Abbreviations: CI confidence interval; OR: odds ratio; FRS: Framingham risk score. + Reference: Sex: Male; WHtR: $\leq 0.5$; Smoking: No; Body Mass Index: $\leq 25$; Hypertension: No; Diabetes mellitus: No; Bold indicates statistical significance at $p<0.05$.

\subsection{Predictors of Intention to Quit Smoking in At-Risk CVD Groups}

The model for identifying the predictors of intention to quit smoking in the at-risk CVD groups was significant $\left(\chi^{2}=294.09, p<0.001\right)$, with $41.8 \%$ of the variance explained (Table 3). Intention to quit smoking was 1.15-times higher with older age (OR: 1.15, 95\% CI: 1.11-1.20) and 5.95-times higher among women than men (OR: 5.95, 95\% CI: 3.18-11.13). Intention to quit smoking was 1.17-times higher among those who engaged in more muscle training (OR: 5.95, 95\% CI: 1.03-1.33) and 1.27-times higher among those with a higher weekly drinking frequency (OR: 1.15, 95\% CI: 1.11-1.20) (Table 3).

\subsection{Predictors of Intention to Quit Drinking in At-Risk CVD Groups}

The model for identifying the predictors of intention to quit drinking in the at-risk CVD groups was significant $\left(\chi^{2}=15.84, p<0.001\right)$, with $24.3 \%$ of the variance explained (Table 3). Intention to quit drinking was 1.08-times higher with older age (OR: 1.08, 95\% 
CI: 1.05-1.10) and 3.78-times higher among smokers than non-smokers (OR: 3.78, 95\% CI: 2.39-6.00). Intention to quit drinking was 0.68-times lower among those with higher WHtR than those with lower WHtR (OR: 0.68, 95\% CI: 0.48-0.96) (Table 3).

\subsection{Predictors of Intention to Engage in Physical Exercise and Muscle Training in At-Risk CVD Groups}

The model for identifying the predictors of intention to engage in physical exercise in the at-risk CVD groups was significant $\left(\chi^{2}=60.36, p<0.001\right)$, with $7 \%$ of the variance explained (Table 3). Intention to engage in physical exercise was 0.40 -times lower in women than in men (OR: 0.40,95\% CI: 0.27-0.61) and 0.73-times lower in the group with high WHtR than in the group with low WHtR (Table 3).

The model for identifying the predictors of intention to engage in muscle training in the at-risk CVD groups was significant $\left(\chi^{2}=22.62, p=0.002\right)$, with $3.9 \%$ of the variance explained. Intention to engage in muscle training was 1.85-times higher in those with hypertension than in those who were not diagnosed with hypertension (OR: 1.85, 95\% CI: 1.18-2.90) and 1.69-times higher among those with a BMI $>25 \mathrm{~kg} / \mathrm{m}^{2}$ than in those with a lower BMI (OR: 1.69, 95\% CI: 1.23-2.32) (Table 3).

\section{Discussion}

This study presents valuable foundational data for exploring fundamental strategies to lower the incidence of cardiovascular and cerebrovascular disease and develop intervention programs that improve compliance by identifying people's willingness to modify their lifestyle according to their risk of cardiovascular and cerebrovascular disease. This study may provide the basis for planning and implementing health measures aimed at reducing modifiable risk factors for cardiovascular diseases [20].

In this study, intention to quit smoking was higher with increasing age in women than in men, with higher muscle training frequency, and with higher weekly drinking frequency in people at an intermediate or a high risk for cardiovascular and cerebrovascular disease (FRS $\geq 10 \%$ ). These results are contradictory to previous findings on adults and older adults in public health centers in Korea, where men were more willing to quit smoking than women [21,22]. A previous review [23] of studies on cardiovascular risk assessment concluded that the predictive ability of a CVD risk score depends on the population being assessed. Therefore, the tools need to be epidemiologically relevant to the population. More research is needed to determine an appropriate and reliable tool.

The higher intention to quit smoking among women in our study seems to reflect the social trend that still renders female smoking taboo. Furthermore, people who frequently engaged in muscle training were more willing to quit smoking, suggesting that people who practice health behaviors are more likely to self-examine the effects of their health behaviors and modify their lifestyle [24]. Thus, specific information about the effects of quitting smoking and physical activity on health should be used to motivate people at risk of cardiovascular and cerebrovascular diseases to modify their lifestyle.

In this study, old age, elevated WHtR, and current smoking were identified as the predictors of intention to quit drinking. Similarly, a previous cohort study on adults aged 40-69 years showed that tendency to quit drinking increased with advancing age [25]. Furthermore, while smoking, drinking, and WHtR increased with increasing FRS, the high-risk group engaged in less physical activity, calling for strategies that promote specific lifestyle behaviors. These results are similar to those of a Lebanese study, where more than $70 \%$ of the participants chose the socially desirable answer but demonstrated low compliance with physical exercise, weight loss, and smoking cessation [26].

Increased WHtR indicates abdominal obesity and because the risk for CVD is higher in those with greater visceral fat even with the same body weight [27], management of abdominal obesity is highly important. Physical exercise is a crucial intervention to reduce abdominal obesity [28]. However, the 2014 KNHANES reports showed that compliance with moderate- or high-intensity physical activity in middle-aged adults (45-64 years) is only $22.9 \%$ in men and $16.4 \%$ in women [5], highlighting the urgency of developing 
physical exercise intervention programs that can reduce central obesity. The reasons for not increasing physical activity despite having CVD risk factors were identified as lack of knowledge about the benefits of exercise and lack of positive attitude toward exercise [29]. Hence, it is important to first motivate individuals to engage in physical activity and increase their self-efficacy [30]. Furthermore, women had 0.40-times lower intention to engage in physical exercise than men, and people with high WHtR were 0.73-times less willing to engage in physical exercise than those with low WHtR. These results are in line with previous findings on 1655 adults in Spain, where physical activity frequency decreased with increasing abdominal obesity and being overweight [28]. Although it is difficult to directly compare our results with the literature because of the lack of studies that directly asked about intention to exercise, a study comparing 2147 men and women in Taiwan reported that exercise compliance was higher in men than in women [31], which is in line with our findings. Therefore, subsequent studies should examine compliance with and willingness to engage in exercise between men and women and develop customized exercise programs for both sexes.

In the present study, hypertension and obesity were confirmed as the predictors of intention to engage in muscle training in at-risk CVD groups. As emphasized by the AHA guidelines [19], with the importance of muscle training in preventing CVD and in lowering the associated mortality, muscle training becomes more important with advancing age [32]. Our results showed that only $20.3 \%$ of the intermediate-risk group and $24.9 \%$ of the highrisk group engaged in muscle training, hence highlighting the importance of strategies that instill self-efficacy and inform individuals about the outcomes of exercise, for example it is recommended, to promote muscle training [33].

Additionally, in terms of lifestyle and comorbidities according to FRS in this study, the rates of smoking and drinking in the high-risk group were $75.6 \%$ and $41.6 \%$, respectively, while the percentages of those engaging in high-intensity exercise and muscle training were $12.4 \%$ and $24.9 \%$, respectively. This shows that people at high risk for CVD fail to modify their lifestyle even though they need to further strive to reduce their risk factors and manage their health [34].

This study has a few limitations. First, the sample was conveniently sampled, thus the findings have limited generalizability. Therefore, a multicenter study that utilizes tools to examine various cardiovascular and cerebrovascular disease risk factors should be conducted. Second, this was a cross-sectional study that investigated the intention to modify lifestyle using a self-report questionnaire, so respondent bias may exist. In addition, causality between cardiovascular disease and lifestyle cannot be determined. Therefore, longitudinal studies that implement a long-term lifestyle modification intervention and examine its effects on reducing the prevalence of cardiovascular and cerebrovascular disease are needed. Despite these limitations, this study is meaningful in that it confirmed the intention to modify the lifestyle habits for the risk factors of cardiovascular disease, centering on those with high cardiovascular risk who actually need lifestyle improvement.

\section{Conclusions}

This study identified the predictors of intention to modify lifestyle behaviors like smoking, drinking, physical activity, and muscle training, in people at risk for CVD. The findings were based on the FRS data of 1229 individuals aged 30-74 years without cardiovascular and cerebrovascular disease who visited a health examination center in Korea.

The results showed that old age, being female, high muscle training frequency, and high drinking frequency are predictors of intention to quit smoking, while old age, low WHtR, and current smoking are the predictors of intention to quit drinking in at-risk CVD groups. Further, intention to engage in physical activity was 0.27 -times lower among women; that is, intention to engage in physical activity was higher for males and those with low WHtR (no abdominal obesity), whereas the intention to engage in muscle training was higher in those with hypertension and higher BMI. 
Intention needs to be supplemented by other, more proximal factors that might compromise or facilitate the enactment of intentions. These differences can be overcome by promoting self-efficacy for behavior modification and establishing educational strategies for specific behavior modification, which may help bridge the intention-behavior gap.

Author Contributions: Conceptualization, J.S. and K.K.; methodology, J.S.; software, K.K.; validation, J.S. and K.K.; formal analysis, J.S.; investigation, K.K.; resources, K.K.; data curation, J.S.; writingoriginal draft preparation, J.S.; writing - review and editing, K.K.; visualization, J.S.; supervision, K.K.; project administration, J.S.; funding acquisition, J.S. All authors have read and agreed to the published version of the manuscript.

Funding: This work was supported by the National Research Foundation of Korea, grant number NRF-2018R1C1B5085623.

Institutional Review Board Statement: The study was conducted according to the guidelines of the Declaration of Helsinki, and approved by the institutional review board of the research facility (IRB No. 130750-202002-HR-001) prior to data collection.

Informed Consent Statement: Informed consent was obtained from all participants involved in the study.

Data Availability Statement: The data presented in this study are available on request from the first author.

Conflicts of Interest: The authors declare no conflict of interest. The funders had no role in the design of the study; in the collection, analyses, or interpretation of data; in the writing of the manuscript, or in the decision to publish the results.

\section{References}

1. Korea Statistics. Available online: http:/ / kostat.go.kr/portal/korea/kor_nw/1/6/2/index.board (accessed on 22 September 2020).

2. Perk, J.; De Backer, G.; Gohlke, H.; Graham, I.; Reiner, Ž.; Verschuren, M.; Albus, C.; Benlian, P.; Boysen, G.; Cifkova, R.; et al. European Guidelines on cardiovascular disease prevention in clinical practice (version 2012): The Fifth Joint Task Force of the European Society of Cardiology and Other Societies on Cardiovascular Disease Prevention in Clinical Practice (constituted by representatives of nine societies and by invited experts) Developed with the special contribution of the European Association for Cardiovascular Prevention \& Rehabilitation (EACPR). Eur. Heart J. 2012, 33, 1635-1701. [CrossRef] [PubMed]

3. Korea Centers for Disease Control and Prevention. Available online: https://www.gov.kr/portal/locgovNews/2241201 (accessed on 25 August 2020).

4. Go, A.S.; Mozaffarian, D.; Roger, V.L.; Benjamin, E.J.; Berry, J.D.; Blaha, M.J.; Dai, S.; Ford, E.S.; Fox, C.S.; Franco, S.; et al. Executive summary: Heart disease and stroke statistics-2014 update: A report from the American Heart Association. Circulation 2014, 129, 399-410. [CrossRef]

5. Korea Centers for Disease Control and Prevention. Available online: http:/ /www.cdc.go.kr/CDC/intro/CdcKrIntro0504.jsp? menuIds=HOME006-MNU2804-MNU2942-MNU2944\&cid=136662 (accessed on 5 January 2018).

6. ADA. Cardiovascular Disease Risk Factors. Available online: http://ada.com/cardiovascular-disease-risk-factors/\#: \{\}: text=Non-modifiable\%20cardiovascular\%20disease\%20risk, or\%20controlled\%20with\%20altered\%20behavior (accessed on 20 November 2018).

7. Koene, R.J.; Prizment, A.E.; Blaes, A.; Konety, S.H. Shared risk factors in cardiovascular disease and cancer. Circulation 2016, 133, 1104-1114. [CrossRef] [PubMed]

8. Hajar, R. Risk factors for coronary artery disease: Historical perspectives. Heart Views 2017, 18, 109. [CrossRef] [PubMed]

9. Byrne, D.W.; Rolando, L.A.; Aliyu, M.H.; McGown, P.W.; Connor, L.R.; Awalt, B.M.; Holmes, M.C.; Wang, L.; Yarbrough, M.I. Modifiable healthy lifestyle behaviors: 10-year health outcomes from a health promotion program. Am. J. Prev. Med. 2016, 51, 1027-1037. [CrossRef]

10. Roerecke, M.; Rehm, J. Alcohol consumption, drinking patterns, and ischemic heart disease: A narrative review of meta-analyses and a systematic review and meta-analysis of the impact of heavy drinking occasions on risk for moderate drinkers. BMC Med. 2014, 12, 1-11. [CrossRef]

11. Jahangiry, L.; Farhangi, M.A.; Rezaei, F. Framingham risk score for estimation of 10 years of cardiovascular diseases risk in patients with metabolic syndrome. J. Health Popul. Nutr. 2017, 36, 36. [CrossRef]

12. Prevention of Cardiovascular Disease. Available online: https://www.who.int/cardiovascular_diseases/guidlines/Full\%20text. pdf (accessed on 14 May 2014).

13. Wilson, P.W.; D'Agostino, R.B.; Levy, D.; Belanger, A.M.; Silbershatz, H.; Kannel, W.B. Prediction of coronary heart disease using risk factor categories. Circulation 1998, 97, 1837-1847. [CrossRef] 
14. Kwon, S.K.; Kim, E.J.; Kim, I.S.; Park, D.H.; Wang, D.L. Difference of Prevalence and Cardiovascular Risk between Waist Circumference and Waist-Height Ratio in Diagnostic Criteria of Metabolic Syndrome. Korean J. Fam. Pract. 2017, 7, $202-206$. [CrossRef]

15. Lee, K.H.; Lee, S.B. Effect of lifestyle on cardiovascular risk in 10 years according to Framingham risk score of middle-aged women-The based on 2016 Korea National Health and Nutritional Examination Survey. Korea Soc. Wellnes 2018, 1, 77288. [CrossRef]

16. Kim, K.H.; Hyun, D.W.; Kim, W.S.; Yang, J.K.; Kwon, T.G.; Bae, J.H. Carotid intima media thickness is associated with the Framingham Risk Score in Korean patients with coronary arteriosclerosis-association between IMT and Framingham Risk Score. Korean Circ. J. 2007, 37, 425-431. [CrossRef]

17. Ku, I.H.; Lee, J.H.; Kim, S.M.; Kang, S.M.; Kim, H.K.; Kim, D.K.; Choi, J.S.; Park, S.K. Identification of a Link between Framingham Risk Score and Fracture Risk Assessment Tool. Korean J. Med. 2015, 5, 547-554. [CrossRef]

18. Sigmundová, D.; Sigmund, E.; Hamrík, Z.; Kalman, M.; Pavelka, J.; Frömel, K. Sedentary behaviour and physical activity of randomised sample of Czech adults aged 20-64 years: IPAQ and GPAQ studies between 2002 and 2011. Cent. Eur. J. Public Health 2015, 23, S91-S96. [CrossRef] [PubMed]

19. Piercy, K.L.; Troiano, R.P.; Ballard, R.M.; Carlson, S.A.; Fulton, J.E.; Galuska, D.A.; George, S.M.; Olson, R.D. The physical activity guidelines for Americans. JAMA 2018, 320, 2020-2028. [CrossRef]

20. Duarte-Clíments, G.; Mauricio, T.F.; Gómez-Salgado, J.; Moreira, R.P.; Romero-Martín, M.; Sánchez-Gómez, M.B. Assessment of cardiovascular risk factors in young adults through the nursing diagnosis: A cross-sectional study among in-ternational university students. Healthcare 2021, 9, 91. [CrossRef] [PubMed]

21. Noh, Y.M.; Lee, Y.; Kim, J.Y.; Noh, J.W. Factors affecting intention to quit smoking of current smokers by gender. J. Korea Contents Assoc. 2019, 19, 321-328.

22. Kim, J.S.; Yu, J.O.; Kim, M.S. Factors contributing to the intention to quit smoking in community-dwelling elderly smokers. J. Korean Acad. Community Health Nurs. 2012, 23, 358-365. [CrossRef]

23. Sacramento-Pacheco, J.; Duarte-Clíments, G.; Gómez-Salgado, J.; Romero-Martín, M.; Sánchez-Gómez, M.B. Cardiovascular risk assessment tools: A scoping review. Aust. Crit. Care 2019, 32, 540-559. [CrossRef] [PubMed]

24. Taylor, A.; Thompson, T.P.; Ussher, M.; Aveyard, P.; Murray, R.L.; Harris, T.; Preece, D. Protocol: Randomised controlled trial of tailored support to increase physical activity and reduce smoking in smokers not immediately ready to quit: Protocol for the Trial of physical Activity-assisted Reduction of Smoking (TARS) Study. BMJ Open 2020, 10. [CrossRef]

25. Park, J.E.; Ryu, Y.; Cho, S.I. The association between health changes and cessation of alcohol consumption. Alcohol Alcohol. 2017, 52, 344-350. [CrossRef]

26. Ghaddar, F.; Salameh, P.; Saleh, N.; Farhat, F.; Chahine, R.; Lahoud, N.; Hleyhel, M.; Zeidan, R.K. Noncardiac Lebanese hospitalized adult patients' awareness of their coronary artery disease risk factors. Vasc. Health Risk Manag. 2018, $14,371$. [CrossRef]

27. Després, J.P. Obesity and cardiovascular disease: Weight loss is not the only target. Can. J. Cardiol. 2015, 31, 216-222. [CrossRef]

28. Suliga, E.; Cieśla, E.; Rębak, D.; Kozieł, D.; Głuszek, S. Relationship between sitting time, physical activity, and metabolic syndrome among adults depending on body mass index (BMI). Med. Sci. Monit. 2018, 24, 7633. [CrossRef] [PubMed]

29. Saber, F.; Shanazi, H.; Sharifirad, G.; Hasanzadeh, A. Checking the determinants of physical activity based on the theory of planned behavior in the housewives. J. Educ. Health Promot. 2014, 3, 94. [CrossRef] [PubMed]

30. Alharbi, M.; Gallagher, R.; Neubeck, L.; Bauman, A.; Prebill, G.; Kirkness, A.; Randall, S. Exercise barriers and the relationship to self-efficacy for exercise over 12 months of a lifestyle-change program for people with heart disease and/or diabetes. Eur. J. Cardiovasc. Nurs. 2017, 16, 309-317. [CrossRef]

31. Mao, H.Y.; Hsu, H.C.; Lee, S.D. Gender differences in related influential factors of regular exercise behavior among people in Taiwan in 2007: A cross-sectional study. PLoS ONE 2020, 15, e0228191. [CrossRef]

32. Carbone, S.; Kirkman, D.L.; Garten, R.S.; Rodriguez-Miguelez, P.; Artero, E.G.; Lee, D.C.; Lavie, C.J. Muscular strength and cardiovascular disease: An updated state-of-the-art narrative review. J. Cardiopulm. Rehabil. Prev. 2020, 40, 302-309. [CrossRef] [PubMed]

33. De Bruijn, G.J.; Rhodes, R.E. Exploring exercise behavior, intention and habit strength relationships. Scand. J. Med. Sci. Sports 2011, 21, 482-491. [CrossRef]

34. Lee, M.J.; Kim, M.J. Concept analysis of volition for health behavior practice in patients with chronic disease. J. Korean Acad. Nurs. 2016, 46, 687-696. [CrossRef] [PubMed] 